\title{
Controle de Larvas de Aedes aegypti por Ninfas de libélula (Odonata) sob Condições Laboratoriais
}

\section{Aedes aegypti Larvae Control by Dragonflies (Odonata) Under Laboratorial Conditions}

\author{
Edivaldo Santos Silva-Filho ${ }^{a}$; Talita Guimarães de Araújo-Piovezan*a; José Oliveira Dantas ${ }^{\mathrm{a}}$; Maria de Jesus Silvestrea; \\ Agripino Emanuel de Oliveira Alves ${ }^{\mathrm{b}}$; Genésio Tâmara Ribeiro ${ }^{\mathrm{a}}$
}

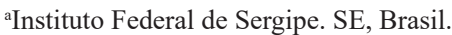 \\ ${ }^{\mathrm{b}}$ Instituto Federal de Alagoas. AL, Brasil. \\ *E-mail: talit_a@hotmail.com
}

\begin{abstract}
Resumo
Estudos para o combate ao vetor Aedes aegypti são importantes para reduzir as incidências da Dengue, Zika e Chikungunya, responsáveis por milhares de mortes no Mundo. Este estudo hipotetiza que as ninfas de odonata influenciam no controle de larvas de Aedes aegypti com eficácia diferente entre as famílias, por terem distinta morfologia de aparelho mastigador e comportamento. O objetivo com esta pesquisa foi avaliar a eficiência de sete famílias de odonata como predadoras de Aedes aegypti, em condições laboratoriais. Ninfas foram coletadas com armadilha de rede, no Rio Poxim Açu e individualizadas, em potes plásticos, com $20 \mathrm{~cm}$ de diâmetro, contendo água do rio e mantidas em temperatura ambiente. Para verificar a potencialidade de predação de larva de Aedes aegypti, pelas ninfas de Odonata, tendo sido avaliada a taxa de predação de 30 larvas de mosquito, em cada pote por dia, contabilizando-se o número de larvas predadas. A média de predação pelas ninfas foi de 6,08 larvas de mosquito por dia. As famílias Aeshnidae $(9,28)$, Libellulidae $(8,37)$ obtiveram as maiores médias de predação por dia. Todas as famílias de odonata predaram, em pelo menos um dia, o máximo de 25 a 30 larvas, exceto Cordulidae. Portanto, os predadores da família Aeshnidae e Libellulidae foram muito eficazes no controle do Aedes aegypti e representam uma alternativa de baixo custo e de fácil aplicabilidade em cisternas e caixas de água domiciliares, que têm condições semelhantes às encontradas neste experimento.
\end{abstract}

Palavras-chave: Agentes de Controle Biológico. Dengue. Vírus Zika.Vírus Chikungunya.

\begin{abstract}
Studies of Aedes aegypti control are especially important for reducing the incidence of Dengue, Zika and Chikungunya cases that are responsible for thousands of human deaths in the world. This study hypothesizes that odonata nymphs influence the Aedes aegypti larvae control with different efficacy among their families, due to their chewing apparatus morphology and to their diverse behavior in nature. The objective was to evaluate the efficiency of seven families of odonata nymphs as predators of the Aedes aegypti larvae under laboratory conditions. Odonata nymphs of seven families were collected with a net trap at Poxim Açu River. Each nymph was placed in a 20-cm diameter plastic recipient containing river water at room temperature. In order to verify the odonata nymphs predation on the Aedes aegypti larvae, the predation rate of 30 mosquito larvae was verified on each recipient per day. The odonata nymphs presented an average predation rate of 6.08 mosquito larvae per day. The families Aeshnidae $(9,28)$ and Libellulidae $(8,37)$ obtained the greatest average predation rate per day. All the Odonata families predated from 25 to 30 larvae in at least one day, except Cordulidae. Therefore, the Ashinadae and libelulidae predators were highly effective on the Aedes aegypti control. Thus, they represent a low-cost alternative for Aedes control in cisterns and water tanks at home sites, which have similar conditions to the ones found in this experiment.
\end{abstract}

Keywords: Biological Control Agents. Dengue Virus. Zika Virus. Chikungunya Virus.

\section{Introdução}

O aumento de ocorrência da Dengue, Zika e Chikungunya tem sido um elemento de extrema preocupação para a sociedade, em função de dificuldades encontradas para combater o vetor. Em 2019, a Organização Mundial de Saúde listou a Dengue como uma das dez doenças de ameaça potencial no mundo. As epidemias de Dengue tendem a ter padrões sazonais e são influenciadas pelos: altos níveis populacionais do mosquito, suscetibilidade a sorotipos circulantes, temperaturas favoráveis do ar, umidade e precipitação. Esses fatores afetam os padrões de reprodução, de alimentação e de desenvolvimento dos mosquitos e, ainda, o período de incubação do vírus transmitido ao Aedes aegypti
(WHO, 2020). Neste mesmo ano, no Brasil, o Ministério da Saúde relatou 1.544.987 casos prováveis de Dengue com 782 óbitos, 132.205 casos prováveis de Chikungunya com 92 óbitos e 10.768 casos prováveis de Zika vírus com três óbitos (BRASIL, 2020).

O Aedes aegypti é o principal mosquito transmissor do vírus da Dengue, Zika e Chikungunya. A fêmea consegue fazer ingestões múltiplas de sangue durante um único ciclo gonadotrófico, ampliando a capacidade de se infectar e de transmitir os vírus. Cada mosquito vive de 30 a 35 dias e, nesse período, as fêmeas põem ovos de quatro a seis vezes, podendo cada uma dar origem a até 1.500 mosquitos (LOPES, 2015). Seus ovos podem permanecer viáveis por até 492 dias na seca, eclodindo após contato com a água, fator que ajuda 
em sua alta incidência (ZARA et al., 2016).

Sua ocorrência é predominante em áreas domésticas ou ao redor de domicílios e de outras construções frequentadas por pessoas, onde se alimentam de sangue humano, tendo como principais depósitos utilizados em sua desova: caixas de água, cisternas, pneus e recipientes plásticos (BRASIL, 2020). Dessa maneira, é essencial que se empregue a ação de controle do mosquito em áreas de alta densidade populacional, que proporcionam alimentação e local para as fêmeas desovarem (LOPES, 2015). Em adição, é importante que sejam investigadas práticas de controle que obtenham melhores respostas no combate à disseminação deste vetor.

O método de controle mecânico tem sido utilizado pelos agentes de endemias das Secretarias Municipais de Saúde Brasileiras, através da eliminação adequada de depósitos naturais ou artificiais de água, que possam servir de criadouro para os ovos do Aedes. Em complementariedade é utilizado o tratamento químico por meio do uso de larvicidas para matar larvas de depósitos em que não é possível eliminar a água e ainda o uso do borrifamento de inseticidas para matar insetos em estágio adulto. Já o controle biológico é pouco empregado (ZARA et al., 2016).

O método de controle químico começou a ser utilizado para combater pragas da lavoura, no início da década de 1940, com o surgimento do Dicloro-difenil-tricloroetano (DDT) (ANDRADE; SANTOS, 2004), mas foi utilizado de maneira desenfreada e até mesmo preventiva, até que os insetos alvo desenvolveram resistência a vários dos compostos químicos, e esses perderam sua eficácia, além de poluírem o meio ambiente, obrigando o homem a buscar novamente meios alternativos, como o controle biológico (ANDRADE; SANTOS, 2004; WERMELINGER; FERREIRA, 2013).

O controle biológico é definido como o uso de inimigos naturais para o controle de determinada praga (CARVALHO et al., 2013) e está contido na própria biodiversidade, minimizando os custos altíssimos no combate de pragas e reduzindo os impactos ambientais (ALHO, 2012).

Em áreas rurais, o Aedes aegypti quase não é observado, em função da presença de predadores naturais (HORTA et al., 2013). Considerando a facilidade de encontrar alguns predadores desse mosquito na natureza e os baixos custos da aplicação desse método de controle biológico, é importante estudar quais predadores têm taxa de predação mais eficiente contra esse vetor.

Peixes, invertebrados aquáticos, patógenos que liberam toxinas, como: bactérias, fungos e parasitas têm sido utilizados no controle biológico de Aedes aegypti. A bactéria Bacillus thuringiensis israelensis (Bti) tem ação larvicida, em função de sua produção de endotoxinas proteicas. Entretanto, apesar de a Bti ser eficaz na redução do número de Aedes imaturos nos recipientes tratados, em curto prazo, não há evidências de que esse método isolado possa impactar na redução da morbidade da dengue em longo prazo (ZARA et al., 2016).
Outra opção foi a introdução da bactéria Wolbachia no Aedes aegypti, que atua bloqueando a multiplicação do vírus dentro do inseto e provocando a esterilidade nos mesmos, quando se reproduzem (FIOCRUZ, 2012). Mosquitos com Wolbachia, ao serem soltos, se reproduzem com os mosquitos locais, eliminando a transmissão das arbovirose (FIOCRUZ, 2012). Entretanto, muitas vezes, as diferenças climáticas, nível de urbanização e de densidade humana local podem limitar o potencial de reprodução dos mosquitos (ZARA et al., 2016), enfatizando a necessidade de mais estudos de controle biológico do Aedes aegypti.

Os insetos da ordem Odonata, conhecidos por libélulas (RAMÍREZ, 2010), são predadores vorazes em todas as fases de vida, predando larvas de mosquitos, de moscas, de abelhas, de besouros, de vespas, e até de outras libélulas (GULLAN; CRANSTON, 2012) e no estágio de vida de larvas imaturas (HAMADA et al., 2014) ou ninfas são aquáticos. Ainda, a maioria das espécies de Odonata demora mais de um ano como uma larva (ninfa), antes de se tornar adulto (RAMÍREZ, 2010).

Raros estudos estimam a predação do mosquito da dengue por ninfas de odonata. Apesar de ter sido observado o sucesso de odonatas na predação de larvas deste mosquito (FAITHPRAISE et al., 2014), não foram avaliadas quais famílias seriam mais eficazes na predação. É provável que a ocorrência de diferenças morfológicas variadas entre as famílias de odonata, desde o desenvolvimento de mandíbulas, de peça bucal mastigadora até de dentes molares e incisivos (HAMADA et al., 2014) influenciem no grau de capacidade de predação de larvas entre famílias.

Este estudo hipotetiza que as ninfas de odonata influenciam no controle de larvas de Aedes aegypti com eficácia diferente entre as famílias, por terem estruturas morfológicas e comportamento diverso na natureza. Apontar famílias de odonata com maior potencial de predação de larvas otimiza a aplicação deste controle biológico na esfera dos órgãos de saúde municipal e estadual de forma a contribuir para o desaparecimento do mosquito e doenças que esse transmite. Portanto, o objetivo com esta pesquisa foi avaliar a eficiência de sete famílias de odonata como predadoras de Aedes aegypti, em condições laboratoriais.

\section{Material e Métodos}

\section{1 Área de estudo}

Este trabalho foi realizado em janeiro de 2017 no Instituto Federal de Sergipe, Campus São Cristóvão. A coleta das ninfas de odonata foi feita em um trecho do Rio Poxim Açu, que corta o Campus São Cristóvão/IFS (1054'48. 35'S $37^{\circ} 11^{\prime} 04.04$ "; $43 \mathrm{~m}$ de altitude). A região tem clima quente e úmido com estação chuvosa de março a agosto (outono e inverno) (SANTOS et al., 2014). O clima local é tropical chuvoso com verão seco, de acordo com a classificação de Koppen. Ninfas de libélulas (ordem odonata) foram coletadas com rede de armadilha tipo D. Posteriormente, 
foram transportadas para o laboratório, em caixas térmicas, para manter a temperatura da água. Em laboratório, as ninfas foram triadas e identificadas em sete famílias: Aeshnidae, Libellulidae, Corduliidae, Gomphidae, Calopterigidae, Coenagrionidae, Megapodagrionidae de acordo com literatura especializada (SOUZA et al., 2007).

Para verificar a potencialidade de predação de larva de Aedes aegypti pelas ninfas de Odonata, cinco ninfas de cada família foram individualizadas, em potes plásticos, de $20 \mathrm{~cm}$ de diâmetro, contendo água do rio e mantidas em temperatura ambiente, totalizando 35 potes plásticos (5 ninfas/pote/ família), durante 30 dias. Em cada pote foram colocadas 30 larvas de Aedes aegypti. A predação foi avaliada diariamente contabilizando a quantidade de larvas predadas.

Foram utilizadas larvas de Aedes aegypti no 3/instar doadas pela Fundação Osvaldo Cruz (FIOCRUZ), Rio de Janeiro, Brasil, da linhagem colônia Rockfeller (12/02/2015), junto ao Laboratório de Parasitologia da Universidade Federal de Sergipe.

\subsection{Análise estatística}

Anormalidade dos dados foi analisada pelo teste de ShapiroWilk. Para investigar as variações nas taxas de predação entre as diferentes famílias das ninfas de Odonata, foi realizado o teste de Kruskal-Wallis para testar as diferenças nas taxas de predação nas larvas. As análises estatísticas foram realizadas usando R (R DEVELOPMENT CORE TEAM, 2017) e o nível de significância para os testes de hipótese foi de $5 \%$.

\section{Resultados e Discussão}

As ninfas de Odonata apresentaram eficiência média de predação de 6,08 larvas de mosquito por dia, entretanto algumas famílias são mais ativas do que outras, dessa forma, as taxas de predação foram significativamente diferentes entre as famílias de Odonata (Kruskal-Wallis $X^{2}=17,667$; g.l. =6; $\mathrm{P}=0,007)$. As famílias Aeshnidae $(9,28 ; 30,9 \%)$, Libellulidae $(8,37 ; 27,9 \%)$ e Megapodagrionidae $(7,08 ; 23,6 \%)$ obtiveram as maiores médias de predação por dia, seguidas de Corduliae $(6,66,22,2 \%)$, Coenagrionidae $(5,64 ; 18,8 \%)$, Calopterigidae $(5,23 ; 17,43 \%)$ e Gomphidae $(3,81 ; 12,7 \%)$ (Quadro 1).

Quadro 1 - Padrão diário de predação de larvas de Aedes aegypti por ninfas de Odonata, considerando um período de 30 dias

\begin{tabular}{|c|c|c|c|c|c|}
\hline Subordem & Família & M (\%) & DP & Mi & Ma \\
\hline \multirow[t]{4}{*}{ Anisoptera } & Aeshnidae & $9,28(30,9 \%)$ & 9,35 & 0 & 30 \\
\hline & Libellulidae & $8,37(27,9 \%)$ & 7,72 & 0 & 30 \\
\hline & Corduliidae & $6,66(22,2 \%)$ & 7,01 & 1 & 8 \\
\hline & Gomphidae & $3,81(12,7 \%)$ & 4,50 & 0 & 25 \\
\hline \multirow[t]{4}{*}{ Zygoptera } & Calopterigidae & $5,23(17,43)$ & 7,54 & 0 & 29 \\
\hline & Coenagrionidae & $5,64(18,8 \%)$ & 8,09 & 0 & 30 \\
\hline & Megapodagrionidae & $7,08(23,6 \%)$ & 8,18 & 1 & 30 \\
\hline & Total & $6,08(20,26 \%)$ & 6,84 & 0 & 30 \\
\hline
\end{tabular}

M: média; DP: desvio padrão por dia e por família. Mi: mínimo; Ma: máximo de predação de larvas predadas em um dia pelas sete famílias de Odonata

Fonte: Dados da pesquisa
Esses resultados corroboram com Andrade e Santos (2004), em que a subordem Anisoptera (Quadro 1) se mostrou mais eficiente na predação de larvas de culicídeos, com média de seis larvas predadas por dia $(20 \%)$. Entretanto, diferem do trabalho de Venkatesh e Tyagi (2015) que encontraram a média de 3,86 larvas por dia.

Analisando individualmente, todas as famílias de odonata aqui estudadas conseguiram predar de 25 a 30 larvas, em pelo menos, um dia, exceto a família Cordulidae, com máximo de oito larvas predadas (Quadro 1). Resultados parecidos foram encontrados por Akram e Ali-khan (2016) em que houve até 50 larvas consumidas em um dia, mostrando que ninfas de odonata são eficientes predadoras no combate àss larvas de mosquito. Entretanto, apenas as famílias Aeshnidae e Libellulidae tiveram taxas de predação mais altas em todos os dias de avaliação.

O instar de ninfa das Odonatas pode variar de dois meses a seis anos, em espécies de clima temperado (GRAND; BOUDOT, 2006). Em países tropicais, as ninfas ocorrem de dois meses a dois anos (SOUZA et al., 2007), sendo comum a ocorrência de ciclos multivoltinos com quatro ou cinco gerações por ano. Existem algumas espécies de partivoltinos que necessitam de três ou mais anos para completarem uma geração (CORBET, 1980; RAVANELLO, 2007).

Levando-se em consideração um período equivalente a um ano, em que as ninfas permanecem no ambiente aquático até se tornarem adultas, é possível estimar que as ninfas de Aeshinidae (9,28 por dia) predariam em média 278,4 larvas em um mês e 3.340,8 em um ano, contribuindo fortemente para a diminuição da população dos mosquitos.

A presença de insetos predadores como o Odonata possibilita a modificação de um ambiente inabitável, com um alto número de mosquitos, para um ambiente habitável por seres humanos, sendo um método eficaz e de baixo custo no controle de mosquito (FAITHPRAISE et al., 2014).

No entanto, é importante frisar que essa estimativa foi feita levando-se em conta as condições laboratoriais, em que o único alimento disponível era de larvas de Aedes aegypti. $\mathrm{Na}$ natureza, as ninfas possuem outras fontes de alimentos (artrópodes, alevinos, girinos) (SOUZA et al., 2007), podendo diminuir a predação de larva de mosquito. Porém, as caixas de água, cisternas, tambores e outros reservatórios de água utilizados pela população humana podem ser equiparados às condições aqui estudadas, uma vez que nestes respectivos locais não existem outras fontes de alimento disponíveis para as ninfas de Odonata, a não ser as larvas de mosquito.

Sendo assim, a predação de larvas de mosquito pelas ninfas de Odonata da família Aeshinidae e Libelulidae é uma estratégia eficiente de controle biológico da população do mosquito e tem como destaque seu baixo custo financeiro.

Para a manutenção do serviço ecossistêmico (predação) realizado pelas libélulas é necessário apenas a conservação dos ecossistemas naturais para que essas possam ali se manter e realizar seu valioso serviço de predação, além de preservar 
a qualidade da água.

\section{Conclusão}

No cenário atual é importante que se busquem alternativas de baixo custo para o controle do Aedes. Os resultados apontaram que as odonatas das famílias Aeshnidae e Libellulidae foram eficazes na diminuição ou controle da população de Aedes aegypti em ambientes, no qual o mosquito é a única fonte de alimento, como é o caso das cisternas e caixas de água dos domicílios.

Sugere-se a utilização das ninfas de odonata em campo para o estabelecimento de um protocolo de controle do vetor e, assim, contribuir para a diminuição/erradicação da Zika, Dengue, Chikungunya e Febre amarela.

\section{Referências}

AKRAM, W.; ALI-KHAN, H. A. Odonate Nymphs: Generalist Predators and their Potential in the Management of Dengue Mosquito, Aedes aegypti (Diptera: Culicidae). J. Arthropod Borne Dis., v. 10, n.2, p.253-258, 2016.

ALHO, C.J.R. The importance of biodiversity to human health: An ecological Perspective. Cad. Estud. Avançados, v.26, n.74, p.151-165, 2012. doi: 10.1590/S0103-40142012000100011

ANDRADE, C.F.S.; SANTOS, L. U. O uso de predadores no controle biológico de mosquitos, com destaque aos Aedes. Artigo técnico. Campinas: Universidade Estadual de Campinas, 2004.

BRASIL. Ministério da Saúde. Boletim Epidemiológico da Secretaria de Vigilância em Saúde n.2, v.51, p.1-16, 2020.

CARVALHO, M.M. et al. Potencial do controle biológico para o controle de Pseudoplusia includens (Walker, 1857) e Anticarsia gemmatalis Hubner, 1818 (Lepidoptera: Noctuidae) em soja. Encicl. Biosfera, v.9, n.17, p.2049-2063, 2013.

CORBET, P.S. Biology of Odonata. Ann. Rev. Entomol., v. 25, p.189-217, 1980.

FAITHPRAISE, F.O. et al. Natural control of the mosquito population via Odonata and Toxorhynchites. Int. J. Innov. Res. Sci. Eng. Technol., v.3, n.5, p.12898-12911, 2014.

FIOCRUZ. Parceria traz para o Brasil iniciativa pioneira de pesquisa em dengue. Fundação Oswaldo Cruz, 2012. Disponível em: $\quad<$ https://agencia.fiocruz.br/parceria-traz-para-o-brasiliniciativa-pioneira-de-pesquisa-em-dengue $>$ Acesso em: 9 jun. 2020.

GRAND, D.; BOUDOT, J.P. Les libellules de France, Belgique et
Luxembourg. Mèze: Biotope, 2006.

GULLAN, P.J.; CRANSTON, P.S. Os insetos: um resumo de entomologia. São Paulo: Roca, 2012.

HAMADA, N.; NESSIMIAN, J. L.; QUERINO, R.B. Insetos aquáticos na Amazônia brasileira: taxonomia, biologia e ecologia. Manaus: INPA, 2014.

HORTA, M.A.P. et al. Os efeitos do crescimento urbano sobre a dengue. Rev. Bras. Prom. Saude, v.26, n.4, p.539-547, 2013. doi: 10.5020/18061230.2013.p539.

LOPES, M. A. O que aprendemos com o Manejo Integrado de Pragas (MIP) da agricultura para o controle do Aedes aegypti: Ponto de vista. Rev. Política Agríc., v.24, n.4, p. 134-136, 2015.

R DEVELOPMENT CORE TEAM. A Language and Environment for Statistical Computing. R Foundation for Statistical Computing, Vienna, Austria, 2017.

RAMÍREZ, A. Odonata. Rev. Biol. Trop., v. 58, n. 4, p. 97-136, 2010.

RAVANELLO, C. T. Diversidade e abundância de larvas de Odonata (Insecta) em nove rios da Bacia Hidrográfica do Alto Rio Uruguai-Santa Catarina. Capecó: Universidade Comunitária Regional de Chapecó, 2007

SANTOS, B.G. et al. Estudo bioclimático das regiões litorânea, agreste e semiárida do Estado de Sergipe para a avicultura de corte e postura. Ciênc. Rural, v.44, p.1-6, 2014. doi: 10.1590/ S0103-84782013005000148

SOUZA, L.O.I.; COSTA, J.M.; OLDRINI, B.B. Odonata. Guia on-line: Identificação de larvas de Insetos Aquáticos do Estado de São Paulo, 2007. Disponível em: <http://sites.ffclrp.usp.br/ aguadoce/Guia_online/index.htm $>$ Acesso em: 9 jun. 2020.

VENKATESH, A.; TYAGI, B. K. Bradinopyga geminata (Anisoptera: Libellulidae) as a predator of Aedes aegypti immatures (Diptera: Culicidae). Int. J. Mosq. Res., v.2, n.3, p.98$105,2015$.

WERMELINGER, E. D.; FERREIRA, A. P. Métodos de controle de insetos vetores: um estudo das classificações. Rev. Panamazonica Saude, v.4, n.3, p.49-54, 2013. doi: 10.5123/ S2176-62232013000300007

WHO. Dengue and severe Dengue: overview. World Health Organization, 2020. Disponível em:https://www.who.int/healthtopics/dengue-and-severe-dengue $\#$ tab=tab_1>Acesso em: 9 jun. 2020.

ZARA, A. et al. Estratégias de controle do Aedes aegypti: uma revisão. Epidemiol. Serv. Saude, v.25, n.2, p.39-44, 2016. doi: 10.5123/S1679-49742016000200017. 